ESTUdIOS INTERNACIONALES I 58 (2007) - ISSN 07 I 6-0240 • I79-2I 2 Instituto de Estudios Internacionales - Universidad de Chile

\title{
Argentina y Chile: el conflicto del gas, factores de política interna Argentina
}

\section{Argentine domestic policy and the conflict over gas exports to Chile}

\author{
Carlos Huneeus*
}

\section{Resumen}

El artículo examina la influencia de los factores políticos en la decisión del gobierno argentino del presidente Nestor Kirchner en 2004 de disminuir las exportaciones de gas natural a Chile y la política seguida por el gobierno de Chile para enfrentar esta dificil situación. En primer lugar, se presentan los factores políticos y económicos que llevaron a los gobiernos de Chile y Argentina a suscribir los acuerdos que hicieron posible las inversiones que permitieron exportar gas natural a Chile; se describe la industria del gas en ambos países, para luego examinar los factores de política interna que llevaron al gobierno argentino a decretar las restricciones en los envíos de gas natural y a aumentar sus precios a través a nuevos impuestos, se analiza la política seguida por el gobierno chileno de los presidentes Ricardo Lagos y Michelle Bachelet para enfrentar esta situación y el impacto económico de la crisis del gas y sus repercusiones en la opinión pública chilena. El artículo muestra el fuerte

Profesor asociado, Instituto de Estudios Internacionales, Universidad de Chile (corpcerc@ rdc.cl). Este artículo se ha preparado en el marco del proyecto Fondecyt Nr. 1050627. Agradezco a Rodrigo Cuevas, del CERC, en la recopilación de antecedentes y a Felipe Muñoz del Instituto de Estudios Internacionales por el análisis de las consecuencias económicas para Chile. Agradezco, asimismo, a las numerosas personas que entrevisté en Buenos Aires y Santiago, especialmente a Waldemar Coutts, Rodolfo Freyre y Jorge Rodríguez. La responsabilidad del artículo es del autor.

Recibido el 7 de agosto de 2007 y aceptado el 13 de septiembre de 2007. 
impacto de las decisiones presidenciales en la política exterior, hecho relevante para comprender la política interna y externa de Kirchner.

Palabras clave: Chile, Argentina, política energética, presidencialismo, conflicto.

\section{Abstract}

This article analyses the political factors that led the Argentinian government of president Nestor Kirchner to reduce exports of natural gas to Chile and increase its price through new export taxes. First, the political and economic preconditions that might explain these decisions are examined in detail, secondly the natural gas industry in Chile and Argentina is considered, to be followed by an analysis of policies pursued by the Chilean presidents Ricardo Lagos and Michelle Bachelet in order this problem, which has had significant economic impact upon the Chilean economy and its public opinion and which are considered in the final section of the article. The article shows the influence of national factors in decisions affecting foreign policy, which contributes to explain president's Kirchner's politics.

KEYwords: Chile, Argentina, energy policy, presidentialism, conflict. 
Carlos Huneeus • Argentina y Chile: el conflicto del gas...

\section{EL PROBLEMA}

El artículo examina la influencia de los factores políticos que explican la decisión del gobierno argentino de disponer la disminución de las exportaciones de gas natural a Chile y la política seguida por el gobierno de Chile para enfrentar esta compleja situación. Se organiza de la siguiente manera: primero se presentan los intereses políticos que llevaron a los gobiernos de Chile y Argentina a suscribir los acuerdos que hicieron posible las inversiones que permitieron la exportación de gas natural a Chile; a continuación, se describe la industria del gas en ambos países, para luego examinar los factores de política interna que llevaron al gobierno argentino a decretar las restricciones en los envíos de gas natural. Se analiza después la política seguida por el gobierno chileno para enfrentar esta situación, el impacto de la crisis del gas en la opinión pública y en la economía chilenas, para terminar con las conclusiones.

La decisión argentina consistió no solo en restringir los suministros desde comienzos del 2004 hasta el momento en que se escriben estas páginas (abril de 2007), sino que abarcó cortes en los envíos, que obligaron a las empresas chilenas a asegurar su funcionamiento utilizando otra fuente energética, especialmente petróleo, además obligó a operar las plantas eléctricas a carbón y se establecieron nuevos impuestos a las exportaciones de gas natural, todo lo cual aumentó el costo económico para las empresas. En Chile, estas medidas provocaron serios problemas al sector eléctrico, que era el principal consumidor de gas ${ }^{1}$ y a las industrias que se habían reconvertido a este bien, en especial a manufactureras de la región metropolitana ${ }^{2}$. Esto fue ampliamente difundido por los medios de comunicación, que llamaron la atención sobre el incumplimiento de compromisos internacionales por Argentina. En efecto, ambos países habían suscrito acuerdos internacionales que aseguraban la exportación de gas a Chile, desde 1997, mediante inversiones de gran envergadura, incluida la construcción de un gasoducto en la zona central y dos en el norte del país. Además, permitió la instalación de una central eléctrica en Salta, Argentina, completamente dedicada a Chile a través de una nueva línea eléctrica. Hasta que comenzó la restricción del envío de gas natural argentino este había tenido un rol muy positivo en el desarrollo económico de Chile, pues permitió ahorrar alrededor de 2 mil millones de dólares por concepto de costos entre 1998 y 2003 (Galetovic, Hinostroza y Muñoz, 2004).

Este escenario implicó un cambio de las reglas del juego establecidas en

1 Un 94\% del consumo de gas en la zona norte proviene del sector eléctrico y $66 \%$ en la zona central. Discurso del ministro de economía, Jorge Rodríguez, en la Cámara de Diputados, sesión 85, 12 de mayo 2004.

2 «Industriales arremeten contra Metrogas. Piden que asuma los sobrecostos de la crisis que están generando los cortes de gas natural argentino», Diario Financiero, 1 de junio de 2004, p. 3. 
acuerdos internacionales suscritos por ambos países, en virtud de los cuales se celebraron contratos entre empresas de ambos países y alentó el nacionalismo latente en amplios sectores de la opinión pública chilena, dañando la imagen de Argentina ante los chilenos.

Estos factores políticos se originaron, en primer lugar, en las difíciles condiciones que enfrentó Argentina y que llevaron a una grave crisis económica en diciembre del 2001 debido al fracaso de la política de la convertibilidad del gobierno del presidente Carlos Menem (PJ, 1989-1999), que condujo a la renuncia del presidente Fernando de la Rúa el 19 de diciembre (Mustapic 2005), elegido dos años antes y a una situación de inestabilidad en que se sucedieron cuatro presidentes en menos de un mes. Finalmente, Eduardo Duhalde (PJ, 2002-2003) pudo asumir el liderazgo que trajo consigo la estabilidad política y condujo al país al restablecimiento del orden político y económico. La salida de la crisis involucró la conversión de las deudas en dólares a pesos argentinos y la congelación de las tarifas de diversos servicios públicos por el gobierno de Duhalde.

Se explica, en segundo lugar, por componentes institucionales del sistema político argentino, entre los cuales se destaca la centralidad decisoria del presidente, definida por las tener atribuciones explícitas que le han entregado la Constitución y las leyes, por las facultades que asume en los espacios que le proporciona el sistema político y por el tipo de liderazgo que ha ejercido el presidente Néstor Kirchner (PJ) (2003-2007). Contrariamente a lo que se podría esperar a la luz de la débil base electoral con que llegó a la Casa Rosada en mayo de $2003^{3}$. Kirchner ha sido, desde un comienzo, un poderoso actor del sistema político argentino. Priorizó la consolidación de su autoridad y poder, sin considerar las repercusiones internacionales, lo que demostró en el conflicto con los acreedores internacionales que tensionaron las relaciones con países desarrollados como Italia, al oponerse la construcción de una planta de celulosa en Uruguay, próxima al territorio argentino, y en el conflicto del gas con Chile. A juicio de Kirchner, las repercusiones internacionales de sus decisiones de política interna eran costos inevitables para el éxito de su gestión.

Este conflicto fue muy lamentable porque la presencia de gobiernos democráticos a ambos lados de la cordillera, restablecida la democracia en Argentina en 1983 y en Chile en 1990, había permitido impulsar una estrecha política bilateral en diversos ámbitos, que incluyó solucionar durante el gobierno de los presidentes Patricio Aylwin y Carlos Menem (PJ,1989-1999) casi todos los proble-

\footnotetext{
Apenas recibió un 23\% de los votos, explicable por la división del voto del partido peronista en tres candidaturas. No hubo segunda vuelta, que seguramente la habría ganado cómodamente, porque el segundo candidato, Carlos Menem, renunció a ella para impedir una victoria de Kirchner que lo hubiera fortalecido.
} 
mas de límites pendientes. Hubo grandes avances en los temas de defensa nacional, que crearon nuevas bases de confianza entre las instituciones armadas de ambos países y superaron el clima de antagonismo que había predominado en el pasado, especialmente con la amenaza de guerra en 1978. Se impulsó una estrecha relación económica en comercio e inversiones, que en los años noventa incluyó la activa participación de empresarios chilenos en la privatización de las empresas eléctricas trasandinas.

Parlamentarios, dirigentes de los partidos de la oposición y expertos en temas de energía criticaron en duros términos al gobierno trasandino por haber roto un compromiso establecido en un tratado internacional ${ }^{4}$. Personalidades de la oposición calificaron de débil la reacción de las autoridades nacionales, lo cual habría favorecido la postura trasandina.

El análisis de las causas y el desarrollo del problema del gas son muy interesantes para comprender la diversidad de causas de política interna que influyen en las decisiones nacionales, que tienen repercusiones internacionales, y la complejidad de los factores que influyen en las decisiones presidencia-

\footnotetext{
Sebastián Bernstein, destacado experto en temas de energía y ex secretario de la Comisión Nacional de Energía durante el régimen militar, sostuvo que Chile debía exigir compensaciones económicas ante la justicia, "Los chilenos hemos sido rehenes», El Mercurio, sábado 10 de abril de 2004, p. B18.
}

les. No era imprescindible que Argentina adoptara la decisión de cortar las exportaciones de gas, pero ello se hizo porque el presidente Kirchner priorizó la satisfacción de las necesidades económicas y políticas internas y asumió el costo de las repercusiones internacionales de su decisión. Ella pone de relieve la necesidad de examinar el rol del presidente en el sistema político no solo teniendo en cuenta los recursos institucionales que le proporciona el orden constitucional y legal ${ }^{5}$, la magnitud del apoyo electoral con que fue elegido, el respaldo con que cuenta en el Congreso y el grado de control que ejerce sobre su partido o los partidos que lo apoyan, como lo resaltan los estudios sobre el presidencialismo (Shugart y Carey 2003; Cheibub 2007) sino también el tipo de liderazgo que ejerce, que le permite utilizar de muy distinta manera la variada y compleja red de recursos institucionales y políticos que le proporciona el sistema político (Neustradt, 1990; Greenstein, 2002). Este poder se apoya en el control del partido del presidente, en su capacidad de negociar acuerdos con la oposición, o debilitar o neutralizar esta si no lo consigue, y en sus iniciativas para mantener el control de la agenda, destacando acciones que tienen gran impacto en los medios de comunicación. Estos aspectos son poco analizados en el estudio del presidencialismo en América Latina realizado por es-

5 Usamos el concepto de poder presidencial en el sentido que le da Neustadt (1990). 
pecialistas estadounidenses (Shugart y Mainwaring, 2000), pero sí en estudios llevados a cabo en algunos países de la región, como Brasil (Lamounier, 2003) y Chile (Huneeus, 2005), que han demostrado su importancia en las decisiones de política económica, como las privatizaciones (Llanos, 1999; Llanos y Margherithis, 2001).

\section{INTERESES POLÍTICOS EN EL ACUERDO GASÍFERO}

El problema del suministro de gas tuvo un fuerte impacto económico, porque obligó a las empresas generadoras a emplear petróleo, cuyo precio en el mercado internacional había subido fuertemente, y acarreó enormes costos políticos en Chile, porque puso en tela de juicio la viabilidad de la diversificación de la matriz energética impulsada por los gobiernos democráticos de la Concertación de Partidos por la Democracia de los presidentes Patricio Aylwin (PDC,1990-1994), Eduardo Frei Ruiz-Tagle (PDC,1994-2000) y Ricardo Lagos (PS/PPD, 2000-2006). Esta diversificación se había propuesto alcanzar dos objetivos diferentes, estrechamente vinculados entre sí: disminuir la dependencia de la energía hidroeléctrica a través de la generación térmica y romper la alta concentración de la industria en dos grupos, Enersis y Gener (antes Chilgener), (Jadresic, 2000) que le proporcionaba, especialmente al primero, no solo un enorme poder económico sino también considerable influencia en el sistema político $^{6}$.

El predominio de la energía hidroeléctrica en Chile tenía el gran inconveniente de su alta dependencia de las condiciones climáticas que, en condiciones de sequía, obliga a decretar racionamientos, con los consiguientes perjuicios a los hogares y a las empresas. La sequía más reciente se produjo en 1997 y dificultó el suministro de electricidad. En esa oportunidad quedó de manifiesto el poder que tenía Enersis en el sistema político, porque el gobierno tomó medidas que le favorecieron, al no decretar que asumiera el costo de falla. Esto impidió que hubiera incentivos para que las grandes empresas que consumen electricidad o las empresas eléctricas importaran generadoras para satisfacer la demanda, pues ello habría perjudicado a Endesa, la empresa generadora del grupo. Si se hubiera implementado costo de falla, a la propia Endesa le habría convenido traer plantas de emergencia para no tener que pagarlo, o sea, para evitar el racionamiento. El costo de falla es un precio de escasez que induce a evitar la escasez.

Diversificar la industria de la energía eléctrica con la entrada de nuevos actores era necesario por sólidas razones económicas, pues en el caso de Enersis esta se apoyaba en la integración vertical de la generación, transmisión y

6 En 1995, ambas poseían el 77,7\% de la capacidad instalada de generación del Sistema Interconectado Central (SIC). 
distribución con las empresas Endesa, Transelec y Chilectra, que en 1994 llevaron al Fiscal Nacional Económico a recurrir a la justicia reclamando por las limitaciones a la competencia que ello involucraba (Huneeus 2000).

El gobierno de Aylwin había impulsado una política energética que incluyó la privatización en 1993 de la empresa generadora Edelnor, que fue adquirida por la empresa estadounidense Southern Electric. La administración del presidente Frei Ruiz-Tagle había privatizado la central generadora a carbón Tocopilla, perteneciente a CODELCO, que conservó una minoría de la propiedad, la que fue adquirida por la empresa belga Tractebel. Ambas generadoras pertenecen al Sistema Interconectado del Norte Grande (SING). Además, el gobierno de Frei privatizó la generadora Colbún, que estaba bajo el control de CORFO, que fue adquirida por un consorcio formado por una empresa belga y una chilena perteneciente al grupo Matte, ubicada en el Sistema Interconectado Central (SIC). En cada una de estas privatizaciones, las bases de la licitación establecieron que los postulantes debían ser actores distintos de los que existían en el país, precisamente para provocar la diversificación de los actores del sector, requisito muy cuestionado por el grupo Enersis, que hizo todo lo posible por hacer fracasar la privatización de Colbún (Huneeus, 2000).

El problema de las exportaciones de gas a Chile también fue muy relevante para Argentina, porque el gas natural era una fuente de energía muy importante, ya que representaba el $50 \%$ del consumo interno, cifra muy superior a la del petróleo, que alcanza al $38 \%$ y a la de la energía hidroeléctrica y nuclear, que se eleva al $12 \%$. El peso del gas es aun mayor si se considera la energía eléctrica, porque el $50 \%$ está constituida por la generación térmica a gas, el $40 \%$ por la generación hidroeléctrica y el $10 \%$ por la energía nuclear. A partir de los años ochenta en los hogares argentinos había aumentado enormemente el consumo de gas natural comprimido estimándose que hacia 1996 un $67 \%$ de los hogares contaban con gas, cifra que en las regiones más frías (incluso la metropolitana) se elevaba a $80 \%$ y caía al $41 \%$ en las regiones más cálidas del noroeste (Galano 2000,218). Un $8 \%$ del consumo de gas corresponde al que emplean los vehículos particulares y del transporte colectivo.

Las exportaciones de gas a Chile se apoyaban, en primer lugar, en la firma por los presidentes Aylwin y Menem en 1991 del Acuerdo de Complementación Económica No. 16, cuyo Protocolo No. 2 estableció las bases para la interconexión gasífera entre ambos países, para que Chile pudiera importar gas natural desde Argentina. De acuerdo con dicho Protocolo, los gasoductos deberían operar bajo el sistema de acceso abierto, se fijaba en un máximo de 5 millones de metros cúbicos diarios la cantidad de gas que Argentina podía exportar a Chile, y se establecía que el gas a exportar debía producirse en la cuenca neuquina ${ }^{7}$. Este Protocolo había

Para mayores detalles de este Protocolo original, ver Tabla 1. 
sido apoyado por los altos personeros de las empresas públicas del sector, la ENAP (Empresa Nacional del Petróleo) e YPF (Yacimientos Petrolíferos Fiscales), que veían en la exportación de gas argentino a Chile una oportunidad de potenciar los negocios para ambas empresas y abría nuevas oportunidades para ampliar la cooperación en proyectos de inversión en petróleo y gas en otros países de América Latina.

La firma de este Protocolo impulsó la realización de los primeros estudios para abastecer a Chile de gas natural, entre los cuales cabe mencionar un proyecto liderado por las empresas chilenas Endesa y ENAP y la argentina YPF, conocido como Gasoducto Trasandino y que era llevado adelante por el consorcio TransGas .

Desde un comienzo, el gobierno chileno aclaró que el Estado no asumiría la iniciativa en materia de construcción de gasoductos, pues ello debía corresponder a los privados y que su rol se limitaba a establecer un marco institucional que incentivara la participación de las empresas privadas.

El acuerdo contenía limitaciones que llevaron a modificarlo en junio de 1995 debido a que incluía disposiciones que lo hacían menos atractivo para los inversionistas chilenos (Gamboa y Huneeus, 2007). La modificación del Protocolo se concretó en 1995 y en virtud de ella se eliminaron la limitación

8 Para mayor información sobre la composición de este consorcio y de su competidor, GasAndes, ver punto V de este artículo. de la procedencia del gas a exportar a Chile, permitiéndose que proviniera de cualquier cuenca, y la cuota máxima de gas exportable diariamente. Sin embargo, se agregó una cláusula que estableció que los permisos de exportación se otorgarían en la medida en que no afectaran el abastecimiento interno argentino, disposición vinculada a otra que estableció el principio de «no discriminación» en caso de fuerza mayor o caso fortuito que afectara la infraestructura para la exportación o consumo, a fin de no perjudicar a ninguna de las dos partes. La seguridad del abastecimiento interno fue el argumento utilizado por las autoridades argentinas para justificar la disminución de las exportaciones de gas a Chile, porque así lo contemplaba el Protocolo de 1995. En definitiva, la decisión argentina significó una discriminación contra Chile, cuyas repercusiones el gobierno y las empresas privadas no supieron evaluar, ya que permitía privilegiar la demanda interna a expensas de las exportaciones a Chile.

El negocio del gas natural provocó marcado optimismo en los actores públicos y privados, apoyado en el hecho de que Argentina había estado exportando diariamente 22 millones de metros cúbicos, que representaban un $20 \%$ del consumo de gas argentino. La exportación era principalmente a Chile y una pequeña proporción se enviaba al Uruguay y a Brasil. Sin embargo, tras el dinamismo de los primeros años de buen funcionamiento del acuerdo binacional había ciertas debilidades que 
los actores no habían apreciado debidamente. De partida, una merma de las reservas de gas, que habían aumentado transitoriamente a partir de 1994 pero que luego alcanzaron niveles similares a los de la primera mitad de los años ochenta. En 1996 y 1997 se apreció un fuerte descenso en la exploración de yacimientos gasíferos, que cayó de 165 pozos exploratorios en 1994 a 94 en 1997 debido a malas señales enviadas por la autoridad económica que frenaron las inversiones. De ahí que las inversiones de YPF en exploración cayeran un $40 \%$, lo cual auguraba un complejo escenario futuro (Galano, 2000, 205) el cual no fue considerado por los empresarios chilenos, que confiaban en que el gobierno trasandino respetaría sus compromisos.

A comienzos de enero de 2002 Argentina congeló las tarifas del gas (esta es la verdadera razón del desaliento de las exportaciones de gas y del debilitamiento de las reservas: a las empresas argentinas no les interesa descubrir nuevo gas), pues la ley que derogó la convertibilidad (Ley N ${ }^{\circ}$ 25561-571, de emergencia pública, de 6 de enero de 2002), ordenó renegociar las concesiones con las empresas en un plazo de seis meses, estableciendo que las tarifas no podrían reajustarse mientras no concluyera el proceso de renegociación. Este no se llevó a cabo debido a que el gobierno de Duhalde no tuvo la voluntad política de hacerlo, puesto que ello habría implicado aumentar las tarifas, medida impopular que habría golpeado especialmente a los hogares y al comercio. Kirchner tampoco quiso hacerlo por las difíciles condiciones políticas en que asumió la presidencia. Los posteriores intentos de las empresas por aumentar las tarifas cuando se reactivó la economía fueron detenidos mediante medidas cautelares ante la justicia adoptadas por los particulares, en las que invocaron el argumento jurídico de que no se había concluido la renegociación de los contratos. La reactivación económica provocó un incremento de la demanda interna de gas y la sustitución del consumo del petróleo y sus derivados -cuyos precios quedaron libres- por gas, que quedó con precio fijo, lo que llevó a que se redujeran las reservas gasíferas y creó las condiciones que llevaron a los cortes del suministro a Chile, en un escenario más amplio de congelamiento de la inversión en labores de exploración y explotación de yacimientos nuevos.

La decisión de congelar las tarifas restó incentivos a las empresas para aumentar las exploraciones de gas con el fin de satisfacer el aumento de la demanda interna y cumplir los compromisos con Chile y con la propia Argentina. Se necesitaban enormes inversiones en exploración y explotación de nuevos yacimientos y era indispensable ampliar los gasoductos a Buenos Aires, construidos en un pasado que no correspondía a las necesidades de la principal zona de consumo del país.

Cabe señalar que ni las autoridades de los gobiernos a ambos lados de la cordillera ni los empresarios parecieron inquietarse por posibles limitaciones 
de la oferta de gas trasandino que pudieran producirse en el futuro y poner en peligro el cumplimiento de los compromisos de exportación. Además, el Gpobierno argentino aseguró que no habría cortes en el suministro a Chile y que la situación de escasez se superaría mediante la aplicación de una escala de precios, lo que cumplió solo a medias, y que retornaría el mercado interno del gas a la normalidad. Pese a que en los años ochenta las exploraciones de gas natural no eran significativas, en especial por las turbulencias económicas, los empresarios confiaban en que la desregulación y la privatización de YPF, gran controladora de los yacimientos gasíferos, darían impulso a la exploración y explotación de nuevos yacimientos que permitirían satisfacer plenamente la demanda interna y cumplir con las obligaciones de exportar a Chile.

Los inversionistas chilenos que compitieron por la construcción del gasoducto -Transgas y GasAndes- confiaban en el éxito del negocio debido a que tenían yacimientos en territorio argentino. En el caso de TransGas, el suministro estaría asegurado porque su socio argentino era YPF, principal productor de gas natural argentino, que había sido privatizada y era controlada por la empresa española Repsol. Por su parte, la seguridad de GasAndes se basaba en que Gener, una de las empresas del consorcio, tenía participación en la propiedad de un importante yacimiento de gas natural en la provincia de Neuquén, cuya producción le permitía cum- plir buena parte de sus compromisos en Chile. Hubo general optimismo frente a una inversión que consideraron muy segura y exitosa, que no tendría mayores obstáculos para llevarse a la práctica y que acarrearía considerables beneficios económicos a ambos países.

\section{LA INDUSTRIA DEL GAS EN Chile}

La suscripción por Chile y Argentina del Protocolo de Integración Gasífera (II) proporcionó los incentivos para que las empresas privadas se interesaran en invertir en la construcción del gasoducto que traería el gas a Chile y en promover la reconversión de industrias y hogares al consumo de este bien. Enersis y Gener buscaron participar de manera determinante en la importación del gas natural argentino para controlar la energía de generación térmica. Cada una de estas dos empresas participó en proyectos de inversión para construir un gasoducto que transportara el gas natural a Chile, originándose una intensa competencia, conocida como «la guerra de los gasoductos", que en definitiva fue ganada por Gener (Gamboa y Huneeus, 2007).

Dos fueron los principales consorcios que se disputaron el transporte del gas argentino a Chile, GasAndes y Transgas. El primero estuvo inicialmente formado por las empresas chilenas Gener y Metrogas, las argentinas Techint y CGC (Compañía General de Combustibles), a las cuales se sumó la empresa canadiense Nova Gas Interna- 
tional, que contaba con la tecnología y la experiencia necesarias en el transporte de este producto. La estructura de la sociedad varió a medida que se desarrolló el proyecto y al inaugurarse el gasoducto estaba integrada por cuatro socios, que se distribuyeron la propiedad de la siguiente forma: Nova $(56,5 \%)$; Gener $(15 \%)$, Metrogas $(15 \%)$, y CGC $(13,5 \%)$ (Figueroa/ Smith, 2002: 5) .

GasAndes proyectó la construcción de un gasoducto desde la denominada Estación La Mora en la provincia de Neuquén, en Argentina, que cruzaría hacia Chile por el paso Maipú y de ahí a Santiago. Tendría una longitud total de $463 \mathrm{~km}$ y de acuerdo con la información proporcionada por la empresa, en una primera etapa su costo inicial sería de 284 millones de dólares. En una segunda etapa, se agregaría a esta suma una inversión de 143 millones de dólares por concepto de ampliación del ducto para ampliar el abastecimiento a otras regiones. En consecuencia, el costo total del proyecto GasAndes

\footnotetext{
El consorcio está estructurado sobre la base de la posición dominante de Nova, cuya actividad principal es el transporte del gas. Los otros socios participaban en otras actividades, como la generación eléctrica a partir de gas (Gener) o la distribución de gas (Metrogas). Esta cooperación de las empresas se extendió a otros negocios estrechamente ligados al gasoducto, como en la generación de energía térmica. En el caso de la planta generadora de ciclo combinado Nueva Renca, Gener poseía el 51\%, Nova el 15\% y CGE Chile (controladora de Metrogas) el 10\% (Figueroa/Smith 2002: 153).
}

ascendería a 527 millones de dólares, esto es, bastante inferior al del otro proyecto.

TransGas estaba integrado por las empresas chilenas Enersis y Chilectra (ambas empresas relacionadas y que tenían una participación de $35 \%$ en el proyecto), la empresa estatal Empresa Nacional de Petróleos (ENAP), con el $10 \%$, la estadounidense Tenneco Gas (25\%), YPF $(10 \%)$, y algunas petroleras argentinas más pequeñas, con el $10 \%$. El gasoducto propuesto se extendería desde la localidad de Loma de la Lata en la provincia de Neuquén (Argentina), para luego cruzar la cordillera a la altura de Chillán y desde ahí avanzar hasta Santiago por la zona central chilena, estableciendo puntos de entrega entre las Regiones Octava y Quinta. La extensión total del ducto, incluyendo todas las ramas propuestas para atender la demanda en las regiones del sur de Chile, era de $1.381 \mathrm{~km}$. Según informó el consorcio, la inversión ascendería aproximadamente a 600 millones de dólares ${ }^{10}$, cifra que luego tendrían que corregir el alza y que superaría los 800 millones de dólares y que también debe considerarse conservadora.

Para Gener, el gas natural argentino era vital para crecer en el mercado de la generación eléctrica mediante centrales de ciclo combinado, porque el hecho de que Endesa controlara abundantes derechos de agua que le daban amplio margen para crecer y le proporcionaban

10 El Diario, 8 de junio de 1995. 
una poderosa barrera en ingreso de competidores que pudieran poner en peligro su posición dominante, constituía una gran ventaja. Además, Endesa veía en el gas trasandino la posibilidad de diversificar su propia estructura de generación para disminuir su dependencia de los avatares climáticos mediante construcción de plantas de generación térmica, lo cual fortalecía aún más su poder económico y político. Esta ambiciosa aspiración de Enersis era impulsada por José Yuraszeck, empresario que había logrado encabezar el crecimiento del grupo en Chile y en América Latina participando en la privatización de empresas eléctricas en Argentina, Brasil y Colombia.

Ambos proyectos realizaron una intensa labor para ganar la licitación, que incluyó una intensa campaña en los medios de comunicación para obtener el apoyo de la opinión pública.

En definitiva, GasAndes ganó la disputa porque ofreció tarifas más bajas que Transgas, que incluso le permitieron celebrar contratos de suministro con las generadoras Colbún y Endesa, esta última vinculada al proyecto de Transgas, además de sus empresas Gener y Metrogas, que formaban parte del consorcio (Gamboa y Huneeus, 2007).

El gas natural argentino también despertó el interés de las empresas chilenas del norte pertenecientes al Sistema Interconectado del Norte Grande (SING) por abastecer de electricidad a las grandes empresas mineras, lo que aseguraba un importante consumo de un recurso que tenía enorme importancia en los costos de producción. La situación fue aún más competitiva que en el caso de la región metropolitana, porque tres proyectos distintos se disputaron los grandes contratos de suministro de energía eléctrica por las empresas mineras y también se enfrentaron Enersis y Gener. El gasoducto Gas Atacama, cuyos socios principales eran Endesa y CMS de Estados Unidos, que participaría como operadora de un ducto que se construiría desde Salta en Argentina hasta la ciudad de Mejillones en Chile; el Gasoducto Norandino, que tenía como socios a la empresa Tractebel, propietaria de la central Tocopilla, (posteriormente Electroandina) y a Southern Electric, controladora de Edelnor; y el proyecto Interandes, a cargo de Gener, que construiría una línea de transmisión desde Salta hacia Chile, para interconectar ambos países. En definitiva, se llevaron a cabo los tres proyectos, con el cual se produjo el absurdo de que hubiera dos gasoductos, que produjeron una sobreoferta de energía que benefició a las empresas mineras debido a originó una fuerte caída de los precios de la electricidad pero que fue un mal negocio para las empresas eléctricas.

\section{LAS CONDICIONES POLÍTICAS INTERNAS EN ARGENTINA}

Decíamos que el conflicto del gas tiene que entenderse en el contexto decisorio del sistema político argentino, ca- 
racterizado por la centralidad decisoria del presidente y por el tipo de liderazgo ejercido por el presidente Kirchner, que priorizaba los objetivos de política interna, sin considerar sus repercusiones para las relaciones bilaterales. Esta centralización es bastante más marcada que la del primer mandatario chileno. En efecto, además de las atribuciones constitucionales que definen la presidencia con las dos funciones de jefe de Estado y jefe de Gobierno, el sistema político argentino le proporciona al primer mandatario mayores recursos de poder e influencia debido al menor grado de institucionalización, que debilita la modernización del aparato estatal y deja amplio margen para decisiones patrimonialistas y clientelísticas (Waisman, 2003). Esta situación también se refleja en la menor autonomía (Huntington, 1968) de otras instituciones, como el Congreso, los gobiernos provinciales y la Corte Suprema ${ }^{11}$. Por ejemplo, los ministros de la Corte Suprema son elegidos por el senado y el presidente tiene enorme poder en su designación debido a la influencia que ejerce en los legisladores de su partido, como lo hicieron los presidentes Menem y Kirchner (Quiroga, 2005). La menor institucionalización también se traduce en un menor grado de modernización

La autonomía de las provincias se ha visto severamente limitada por la intervención del presidente en sus go-

11 Editorial, «La integración de la Corte Suprema», La Nación, 5 de noviembre de 2006. biernos o a través de su dependencia económica del presupuesto nacional. (Serrafero, 2005). Los gobiernos provinciales no disponen de un orden institucional que les proporcione la autonomía económica respecto del gobierno central que les corresponde de acuerdo con la estructura federal, sino que se encuentran en un considerable grado de subordinación respecto del presidente. Por esta razón, las disputas políticas en las provincias se conviertan en una oportunidad para debilitar al presidente, como ocurrió con la derrota del oficialismo en Misiones, que frenó el proyecto del gobernador de permitir la reelección ilimitada ${ }^{12}$.

El presidente puede intervenir en ámbitos decisorios propios del Congreso mediante la delegación de facultades, especialmente las leyes de emergencia económica, con las cuales han actuado los ministros de economía prácticamente desde que asumió el presidente Carlos Menem en 1989 (Llanos y Margheritis, 2003). Esta ley le permitió al gobierno llevar adelante un ambicioso programa de transformación económica, en la definición de Kloten (1991), es decir, de profundo cambio de las relaciones entre el estado y la economía, que abarcó la desregulación y la privatización de empresas públicas.

También interviene en el ámbito del parlamento a través de los decretos de

12 «Las Misiones, la oposición avanza contra Felipe Solá», La Nación, 31 de octubre de 2006, p.1; «La oposición siente que surge un nuevo escenario político", La Nación, 31 de octubre de 2006, p.5. 
necesidad y urgencia (DNU), que han sido ampliamente utilizados por los presidentes Menem (Ferreira Rubio y Goretti, 1996), de la Rúa y Kirchner y les han permitido ejercer gran influencia en la dirección económica. Con estos recursos constitucionales, el gobierno puede decretar nuevos tributos que le permiten contar con recursos económicos adicionales en fondos fiduciarios que le permiten impulsar sus programas y que administra sin el consentimiento del Congreso.

El presidente goza de un considerable mayor margen de libertad para adoptar decisiones que en un sistema político en que las instituciones tienen roles diferenciados y gozan de un considerable grado de autonomía (Huntington, 1968). Su círculo más íntimo de colaboradores está formado por familiares -su esposa, la senadora Cristina Frenández, y su hermana Alicia, ministra de Desarrollo Social-, colaboradores de gran confianza, que lo acompañaron en su gestión como gobernador en Santa Cruz (1991-2003) -el secretario legal y técnico de la presidencia, Carlos Zannini y el ministro de Planificación, Julio de Vido-y el jefe de gabinete, Alberto Fernández, que no es peronista y que trabajó con Domingo Cavallo cuando durante un breve tiempo fue ministro de economía del presidente de la Rúa. Con ellos, Kirchner ejerce una dirección del gobierno altamente centralizada y personal, en que los demás ministros tienen bajo protagonismo y no son consultados por él respecto de decisiones que afectan su cartera.

Esta enorme cantidad de recursos propios, en un sistema político altamente flexible y con instituciones sujetas a decisiones discrecionales del presidente, provoca una enorme dependencia de los demás actores políticos y económicos respecto del presidente. Los empresarios se encuentran en un escenario político de gran incertidumbre, con la constante amenaza de que se modifiquen las normas institucionales en que deben actuar, que les obligan a adaptarse a condiciones nuevas que plantean nuevas exigencias, tales como la congelación de las tarifas de los servicios básicos, nuevos impuestos a las exportaciones o importaciones y revisión de los contratos suscritos con el Estado. Esta incertidumbre se da especialmente en el caso de las empresas de servicios públicos de electricidad, teléfonos, agua potable y alcantarillado, que fueron privatizadas durante el gobierno de Menem y que son controladas por empresas europeas, especialmente francesas y españoles. El desempeño de estas es frecuentemente evaluado por los dirigentes políticos y algunas de ellas han sido criticadas por el presidente Kirchner, que las acusó de entregar un mal servicio a los usuarios y de no cumplir los contratos de concesión. Por ejemplo, la prensa argentina dio amplia cobertura a las críticas del gobierno a los servicios proporcionados por la empresa privatizada Aguas Argentina, controlada por el grupo francés Suez, que culminaron en la rescisión del contrato de concesión y su posterior renacionalización, pese al 
rechazo que provocó en el gobierno francés ${ }^{13}$.

En este escenario institucional y político, la seguridad jurídica propia de un orden político moderno se ve severamente limitada, obligando a las empresas a buscar mecanismos de seguridad en el propio sistema que pueden aumentar sus componentes patrimonialistas y clientelísticos o buscar el respaldo de sus respectivos gobiernos, que persuaden o presionan a las autoridades para defender los intereses que se ven amenazados.

Entre las empresas eléctricas chilenas presentes en Argentina cabe mencionar Colbún, perteneciente al grupo Matte, que tiene importantes inversiones en la industria de la celulosa a través de la Compañía Manufacturera de Papeles y Cartones (CMPC), con una planta-Bosques del Plata S.A.- en la provincia de Catamarca;.13 Endesa, con importante participación a través de las filiales de la empresa española en la generación y distribución; mientras que Gener también está presente en la generación eléctrica.14 Esto las pone en situación de dependencia de las decisiones de las autoridades argentinas y

13 Memoria CMPC, 2006.

14 Endesa tiene las empresas filiales Endesa Costanera S.A., con un $64,26 \%$ de la propiedad. Hidroeléctrica El Chocón S.A., con el 47,44\%, Endesa Argentina, 99\%, e Hidroinvest S.A. 69,92\%. En empresas coligadas, tiene participación, de $45 \%$ en Comercializadora de Energía del MERCOSUR S.A. (CEMSA). Compañía de Transmisión del Mercosur S.A, $(37,65 \%)$ y Transportadora de Energía S.A, (37,65\%). Memorias Endesa (Chile), 2006. las obligó a ser muy prudentes al momento de decidir cómo reaccionar ante el nuevo escenario de las exportaciones de gas natural a Chile.

\section{KiRCHNER Y LA POLÍtica INTERNACIONAL}

Kirchner ha demostrado que sus decisiones se guían por los objetivos de la política interna y no por los de la política exterior. Esta orientación tiene una larga tradición en el peronismo, en su momento matizada por Carlos Menem, pero recogida por él, lo que se ha traducido en declaraciones de independencia frente a los gobiernos de los países desarrollados, incluso Estados Unidos. Algunas de sus actuaciones frente a gobernantes o grandes empresarios son trivializadas por los observadores, que las describen como manifestaciones de falta de cortesía o fallas protocolares, aunque en verdad se trata de decisiones que concuerdan con su estilo orientado a imponer un liderazgo autónomo y decidido en la política nacional ${ }^{15}$.

Contrariamente a lo que cabría esperar, el hecho de que su madre sea chilena no ha influido en su postura hacia Chile. Su relación con ella ha sido compleja y se desconoce si mantienen algún tipo de relación ${ }^{16}$.

15 En una oportunidad hizo esperar durante 45 minutos a la presidenta de la empresa Hewlett Packard.

16 Carla Fiorina, quien se retiró irritada de la Casa Rosada sin ver a Kirchner. En otra 
Kirchner ha demostrado ser muy autónomo para enfrentar las críticas de los gobiernos europeos que cuestionan sus decisiones. Esto también ha quedado demostrado con sus colegas latinoamericanos, y de manera muy visible con el prolongado conflicto con el gobierno del Uruguay por la construcción por una empresa de Finlandia de una planta de celulosa en la ribera del río Paraná. El incidente ha sido muy grave para el Uruguay, porque se trata de un proyecto de gran envergadura que, al ponerse en marcha tendrá importantes repercusiones para su economía y le permitirá diversificar sus exportaciones, que hasta ahora han girado principalmente en torno a los productos de la agricultura. Sería la mayor inversión privada en la historia del Uruguay y le significaría aumentar su PIB en un $1.6 \%{ }^{17}$. El conflicto se ha

oportunidad, no apareció en una gala en el teatro Colón organizada por el gobierno holandés con motivo de la visita a Buenos Aires de la reina. Es conocido que llegó bastante atrasado al desayuno con presidentes en la Cumbre Iberoamericana, en Bolivia. Véase, «La impuntualidad del Presidente es casi un problema de Estado", La Nacion, 29 de julio de 2004, p.8.

No se le ha visto junto a Kirchner, no ha sido invitada a participar en eventos oficiales y se especula sobre un posible quiebre entre ellos desde su adolescencia (Curia, 2006).

17 El 15 de febrero de 2005 el presidente del Uruguay autorizó la construcción de una segunda planta de celulosa a la ribera del río Uruguay, en la localidad de Fray Bentos (la primera pertenece a una empresa española), que será construida por la empresa finlandesa Botnia. Es la mayor extendido a lo largo de dos gobiernos del país, el del presidente Jorge Battle, del partido Colorado, y el del Frente Amplio del Dr.Tabaré Vásquez, que encabeza una administración de centro izquierda.

El presidente Kirchner tampoco ha variado de posición ante las pésimas consecuencias que este conflicto está produciendo al Mercosur, que pierde legitimidad ante su incapacidad de resolver un conflicto entre dos países miembros ${ }^{18}$. Su firme posición es reconocida por el presidente del Brasil, Lula, quien se ha mantenido al margen del conflicto de Argentina con el Uruguay, porque no quiere tener dificultades con su colega.

Su esposa, Cristina, mantiene relaciones con dirigentes del PS y del PPD chilenos, pero ellas no modifican el estilo de autonomía y firmeza que Kichner mantuvo con el presidente Lagos. Este estilo era también una manera de romper con el desarrollado por Menem con los presidentes Aylwin y Frei Ruiz-Tagle, con los cuales mostró una cercanía que el líder de Santa Cruz ha evitado con Lagos, así como con los demás presidentes de la región.

inversión del sector privado industrial de Finlandia en el exterior <http://www. botnia.com/es/default>.

18 Joaquin Morales Solá, «El aislamiento internacional de la Argentina", $\mathrm{La} \mathrm{Na}$ ción, 30 de julio de 2006. 
Carlos Huneeus • Argentina y Chile: el conflicto del gas...

\section{LA CENTRALIDAD DECISORIA DEL PRESIDENTE EN CHILE}

La capacidad decisoria del presidente chileno es menos centralizada que la de su colega argentino porque el sistema político, que tiene mayor grado de institucionalización, le impide actuar con discrecionalidad. Desde luego, no cuenta con la institución de los decretos de emergencia del presidencialismo argentino y brasileño (Negretto, 2001; 2002) y desde el restablecimiento de la democracia no se ha hecho uso de la delegación de facultades del Congreso en el Ejecutivo. El presidente tiene limitadas atribuciones en materia de política monetaria y fiscal debido a que el Banco Central goza de autonomía legal y económica consagrada en la Constitución (artículos 108 y 109).19

El sistema político ha evolucionado desde 1990 hacia una mayor interdependencia entre el poder ejecutivo y el legislativo, especialmente con el Senado, lo cual ha disminuido la autoridad del presidente y ha fortalecido a la cámara

19 Es dirigido por un Consejo de cinco miembros, elegidos por el Senado a propuesta del presidente, que son profesionales de reconocido prestigio, aunque su elección toma en cuenta las posiciones de los partidos de gobierno y oposición (Nacrur, 2001). La acción del Banco Central no ha sido siempre acertada. Reaccionó en forma muy drástica frente a la crisis asiática que se presentó con fuerza desde 1997, subiendo fuertemente las tasas de interés, lo que perjudicó a muchas empresas y provocó un considerable aumento de la cesantía. alta. Esto ha sido el resultado de reformas constitucionales que han ampliado sus competencias en la designación de altos funcionarios del Estado, en especial la de 2005 (Pfeffer, 2006). Mientras que en Argentina hay un presidencialismo fuerte con un Congreso débil, en Chile este es menos marcado y hay un Congreso fuerte, especialmente el Senado, lo que reafirma su función como importante escenario de debate nacional y su influencia en múltiples esferas de la política nacional, tales como la política exterior, que es el ámbito más claro de la autoridad presidencial ${ }^{20}$.

En la Constitución de 1980, el Senado solo nombraba a los consejeros del Banco Central. En 1989, poco antes del fin del régimen militar, se le entregó la facultad de elegir a los diez miembros del Consejo Nacional de Televisión, organismo encargado de velar por el funcionamiento de la televisión en el país, que serían propuestos por el Presidente de la República. También participa en la designación de los seis miembros del Consejo de Televisión Nacional (TVN) que es el canal público.

Durante el gobierno del Presidente Frei Ruiz-Tagle, en el marco de la reforma judicial se facultó al Senado a designar a los ministros de la Corte Suprema, que son propuestos por el Presidente a partir de una quina en-

20 Por ejemplo, en el envío de tropas chilenas a Haití en el marco de las operaciones de paz de las Naciones Unidas, que deben ser autorizadas anualmente por el Congreso, que obliga al Ejecutivo a una labor de persuasión con los parlamentarios. 
tregada por el más alto tribunal de la República. El Senado también nombra al Fiscal Nacional, autoridad creada por la reforma procesal penal, y que tiene como función dirigir el ministerio público.

A raíz del acuerdo suscrito entre el gobierno del presidente Lagos y la oposición en 2003 en temas de la modernización del Estado y de probidad se creó el Consejo de la Alta Dirección Pública, con la facultad de designar a altos funcionarios de la administración pública integrados al Sistema de Alta Dirección Pública. El Consejo se compone de cuatro personas nombradas por el Senado a propuesta del Presidente y es dirigido por otra, designada por el Presidente. Su función es nombrar a quienes deban ocupar los cargos superiores de la administración pública que son de exclusiva confianza del Presidente y cautelar el profesionalismo e imparcialidad de los procesos de selección de los altos funcionarios ${ }^{21}$.

\section{LA POLÍTICA DEL GOBIERNO CHILENO ANTE LA CRISIS DEL GAS}

El problema del gas argentino fue un balde de agua fría para el Gobierno del presidente Lagos, que había obtenido enormes avances en las relaciones económicas internacionales, con la firma de los tratados de libre comercio con

21 Estos cambios institucionales que han fortalecido al Senado se analizan en $\mathrm{Hu}-$ neeus y Berríos (2004; 2005) y en Huneeus, Berríos y Cordero (2006). la Unión Europea y con los Estados Unidos. No esperaba tener una disputa económica con las autoridades trasandinas, pero tampoco podía seguir una política de confrontación, que habría empeorado la situación.

El gobierno de Kirchner tropezaba con dificultades de abastecimiento para satisfacer la demanda interna que le planteaba altos riesgos políticos debido a la importancia del gas natural para el consumo residencial. A fin de asegurar el consumo interno debió importar gas de Bolivia, que el gobierno del país altiplánico negoció a condición de que no sirviera para satisfacer las necesidades de Chile (sin exportar «ni una molécula» a Chile) y a un mayor precio que el que se cobraba a las empresas chilenas. Argentina cubrió el mayor costo del gas natural boliviano aumentando los impuestos que gravaban la exportación de gas natural a Chile («derechos de retención»), lo que implicó un costo adicional para las empresas chilenas que lo estaban importando, especialmente Metrogas y las eléctricas. Desde julio de 2004 hasta marzo de 2007 las empresas chilenos debieron pagar un total de 309 millones de dólares por este concepto (cuadro 1) De país exportador, Argentina se convirtió en importador de gas.

La estrategia de Chile fue quitar tensión al conflicto con Argentina mediante una estrategia amplia, impulsada especialmente desde el ministerio de economía cuyo titular era el economista Jorge Rodríguez (PDC), que tenía amplio conocimiento del sector eléctrico 
Carlos Huneeus • Argentina y Chile: el conflicto del gas...

CuAdro I: Impuesto de RETENCIÓN A LAS EXPORTACIONES DE

GAS NATURAL A CHILE

\begin{tabular}{|l|c|c|c|}
\hline Mes & Año & $\begin{array}{c}\text { Volumen } \\
\text { MMm3 }\end{array}$ & $\begin{array}{c}\text { Impuesto } \\
\text { MMUSD }^{* *}\end{array}$ \\
\hline Julio & 2006 & 397 & 33 \\
\hline Agosto & 2006 & 978 & 31 \\
\hline Septiembre & 2006 & 406 & 34 \\
\hline Octubre & 2006 & 469 & 39 \\
\hline Noviembre & 2006 & 408 & 34 \\
\hline Diciembre & 2006 & 445 & 37 \\
\hline Enero & 2007 & 478 & 24 \\
\hline Febrero & 2007 & 283 & 38 \\
\hline Marzo & 2007 & 453 & 309 \\
\hline Total & 3.717 & \\
\hline Fuente: "ENARGAS, www.enargas.gov.ar *"Colbún S.A & \\
\hline
\end{tabular}

porque había sido gerente general de una importante generadora privada. Fue acompañado en esto por la Comisión Nacional de Energía, a cargo del abogado Luis Sánchez Castellón (PS). Ambos tenían experiencia política debido a que habían sido militantes activos de sus respectivos partidos, lo que les ayudó a comprender las complejidades de la política interna argentina e iniciar la puesta en marcha de una estrategia de mediano y largo plazo que conduciría a reducir la dependencia de Chile de los envíos de gas natural trasandino mediante la diversificación de la matriz energética.

La participación del Ministerio de Relaciones Exteriores fue marginal porque se quiso que el problema fuera tratado como una cuestión sectorial, de modo que no afectara las relaciones bilaterales, cuyo cuidado es atención preferente de la Cancillería.

La marginación de la Cancillería en las negociaciones bilaterales fue reafirmada por un hecho ajeno al incidente del gas natural y tiene que ver con la designación del nuevo ministro de relaciones exteriores de Chile, Ignacio Walker, que a fines de septiembre del 2004 reemplazó a Soledad Alvear ${ }^{22}$. Kirchner se indignó por el nombramiento de Walker cuando le informaron que en una de sus columnas en un diario capitalino lo había criticado ${ }^{23} \mathrm{y}$ se había expresado en duros términos contra el peronismo ${ }^{24}$. Walker dio expli-

22 Alvear abandonó el gabinete para ser candidata presidencial del PDC para los comicios del 2005.

23 Señaló que «a pesar de haber obtenido sólo el $22 \%$ de la votación, se encuentra empeñado en cuidar su único verdadero capital político: su popularidad». También se recordó que Andrés Velasco, ministro de hacienda de Michelle Bachelet, habría escrito un artículo contra el peronismo, recordando sus rasgos fascistas, «Un ministro chileno afirmó que el PJ tiene "rasgos fascistas», La Nación, 20 de marzo de 2006.

24 En su columna, Walker sostuvo que «el verdadero muro que se interpone entre Chile y la Argentina no es la cordillera de 
caciones públicas de su escrito, aclarando que había actuado en su calidad de académico ${ }^{25}$, mientras que el presidente Lagos señaló que al nombrarlo ministro no conocía el texto del artículo, con lo cual dio a entender que comprendía la irritación trasandina. Kirchner manifestó su molestia, suspendiendo un viaje a Chile ${ }^{26}$, y dejó pasar el incidente, que le había permitido demostrar su autonomía frente al presidente $\operatorname{Lagos}^{27} \mathrm{y}$ de paso impidió que el canciller chileno fuera un interlocutor relevante con su homólogo argentino.

Desde un comienzo se adoptó una postura prudente, que evitara provocar irritaciones que empujaran a Kirchner a tomar medidas que complicaran aún más la situación de las empresas chilenas. La prudencia se justificaba, además, para no irritar a Kirchner, que es sensible a las críticas externas,

los Andes, sino el legado del peronismo y su lógica perversa", caracterizándolo por sus «rasgos autoritarios, corporativos y fascistoides».Walker, Ignacio, «Nuestros vecinos argentinos", El Mercurio, 6 de mayo de 2004, p.2.

25 «Presidente Kirchner sigue furioso con el canciller Walker», La Segunda, 4 octubre 2004, p. 13; Andrés Cisneros, "Walker y su equivocada visión del peronismo", $\mathrm{La}$ Tercera, 6 octubre 2004, p. 3; Antonio Cafiero, "Chile y un ingrato incidente», Clarín, 7 de octubre de 2004.

26 «Se abrió un nuevo conflicto con Chile», La Nación, Buenos Aires, 4 de octubre de 2004; p.12, 2 de octubre de 2004.

27 Morales Solá, Joaquín, «El gobierno archiva el conflicto con Chile», La Nación, Buenos Aires, 7 de octubre de 2004. como se comprobó en el conflicto de las papeleras.

El gobierno buscó «desargentinizar» el problema con una propuesta de largo plazo que pusiera fin a la dependencia de Chile respecto del gas natural trasandino. La propuesta también buscaba expresar la voluntad política del gobierno de avanzar hacia una cooperación regional, que era poco visible por su énfasis en suscribir tratados de libre comercio con la Unión Europea y Estados Unidos y la atención prestada a las relaciones comerciales con los países del Asia-Pacífico. Para asegurar el abastecimiento de gas, Chile abrió una licitación internacional para la construcción de una planta de gas natural licuado (GNL) en Quintero, con un consorcio de empresas en el cual participaba el estado a través de ENAP y la británica British Gas. Este proyecto significa que debería disponerse de este gas el año 2010, con lo cual se dejaría de depender del gas natural argentino.

El segundo objetivo se manifestó en la propuesta de construir un "anillo energético» para atender las necesidades de energía y aprovechar los recursos de los países del Cono Sur, que incluyera la cooperación de Perú, Bolivia, Argentina y Chile y que llevaría a construir un gasoducto que los comunique. La iniciativa era de interés para ell gobierno argentino, al que la participación de Bolivia podría ayudarle a solucionar su propio déficit de gas natural, importándolo de ese país.. La inestabilidad política de Bolivia no era favorable para incorporarlo a una solución regional y 
su desconfianza hacia Chile constituía un obstáculo demasiado importante para hacer posible la iniciativa.

La propuesta del "anillo energético» se vio entrabada por la desconfianza hacia Chile en la opinión pública de los países vecinos del norte. En el caso del Perú, la prensa describió la iniciativa como un proyecto que solo buscaba beneficiar a Chile. El gobierno del presidente Alejandro Toledo no la apoyó, lo que se explica por el hecho de que aplicó una política de distanciamiento de la administración del presidente Lagos, cuyo fundamento se encuentra en su debilitada base de apoyo político y en el escaso respaldo popular que obtenía en las encuestas. Este escenario favoreció la acción de las posturas nacionalistas de políticos y sectores de la intelectualidad peruana, que impidieron un acercamiento en el tema energético.

La iniciativa chilena también tropezó con los poderosos intereses de las empresas privadas del sector. La extracción y comercialización del gas estaba bajo el control de una empresa española, Repsol, que controla YPF luego de su privatización por el gobierno de Menem, que representaba el $70 \%$ de la producción argentina. Repsol también está presente en Bolivia, donde tiene el $80 \%$ de la producción de gas. Esta empresa no vio con buenos ojos la fórmula chilena porque su plan era aprovechar los derechos del gas natural peruano ${ }^{28}$, que extraería para licuarlo en México o los Estados Unidos. Se presentó a la licitación convocada por

28 Los yacimientos de Camisea. el gobierno chileno para la construcción de una planta de GNL de Quintero, pero la perdió

En definitiva, si bien es cierto que la propuesta chilena de construir un «anillo energético» no resultó, tuvo un efecto positivo para Argentina porque aumentó el interés de Bolivia por venderle gas, lo cual era provechoso para Chile porque habría más gas natural en el mercado trasandinoy las empresas podrían exportar parte de él a nuestro país.

La otra medida trascendental que adoptó el Gobierno de Lagos fue dictar una nueva ley eléctrica, la Ley corta II, que impuso el sistema de licitaciones para abastecer a las compañías distribuidoras por períodos de hasta 15 años, permitiendo separar las decisiones de inversión chilenas en plantas generadoras del hecho de disponer o no de gas argentino. El proyecto de ley pertinente fue aprobado por unanimidad en el Congreso Nacional y se logró tramitar en apenas 6 semanas. Como fruto de esta ley, actualmente hay una carrera por invertir en centrales eléctricas.

El cambio de gobierno en Chile con la llegada de Michelle Bachelet a La Moneda y la consiguiente modificación de los equipos ministeriales provocó cambios en la política respecto del problema del gas natural de Argentina. El tema energético fue sacado de la cartera de Economía, que pasó a estar integrado al ministerio de Minería y Energía, bajo la dirección de Karen Poniatchik.La nueva ministra cambió el estilo de persuasión seguido por su antecesor e impulsó una política 
más explícita frente a las autoridades argentinas, con una mayor visibilidad ante los medios de comunicación, convencida de que con ello podría lograr mejores condiciones en el suministro de gas ${ }^{29}$. El nuevo estilo adoptado por la ministra permitió mantener la alta visibilidad del conflicto porque atrajo la atención de la prensa, pero no tuvo resultados favorables para Chile porque 2006 fue el año en que Argentina exportó menos cantidad de gas natural.

Tampoco continuó la política de trabajar en estrecha colaboración con el secretario de la CNE, que ahora correspondía al economista Pablo Serra, ni mantuvo la asesoría de los expertos argentinos que Rodríguez y Sánchez Castellón habían contratado para apoyar su trabajo, que ambos consideraron muy útil para sus negociaciones con la contraparte trasandina.

\section{EL IMPACTO DE LA CRISIS DEL GAS EN LA OPINIÓN PÚBLICA CHILENA}

Decíamos que la decisión argentina de disminuir las exportaciones de gas a Chile tuvo un fuerte impacto en la opinión pública chilena. El problema tuvo una alta visibilidad en los medios de comunicación, reactivando las visiones críticas hacia los argentinos en un am-

29 La ministra, periodista de profesión, concedió un gran número de entrevistas en los medios (42), en 35 de las cuales se refirió al tema de la energía y al problema del gas $<$ www.minmineria.cl $>$. plio sector de la población. Argentina es un país respecto del cual los chilenos tienen opiniones encontradas, positivas en un sector, negativas en otros y con una mayoría de la población sin postura definida debido a que los asuntos internacionales no le interesan mayormente. Esto se explica por la historia de desencuentros, con incidentes limítrofes, que tuvieron gran cobertura de prensa y en que el momento más delicado de las relaciones entre los dos países se produjo por la amenaza de guerra por Argentina en diciembre de 1978, tras desconocer el laudo arbitral de la reina de Gran Bretaña en la controversia sobre las islas del canal de Beagle.

Un antecedente muy interesante para conocer la percepción que tienen los chilenos de la Argentina son los resultados de una encuesta realizada en Santiago por el Instituto de Sociología de la Universidad de Chile en 1957, que replicamos en una encuesta basada en una muestra nacional que se llevó a cabo en agosto de 2006. La encuesta indaga acerca de los países hacia los cuales los chilenos tienen más y menos simpatía y formula dos preguntas muy interesantes para conocer el clima subjetivo existente durante el conflicto del gas.

La encuesta de 1957 se aplicó cuando Argentina avanzaba hacia la democracia después del derrocamiento del régimen del general Perón por acción de los militares, que concluiría al año siguiente con la elección del presidente Arturo Frondizzi. En esa oportunidad, Argentina era el país que concitaba el mayor 


\section{GRÁfico I}

PAíses LATINOAMERICANOS QUE GOZAN DE MÁs SIMPATÍAS, I957-2006

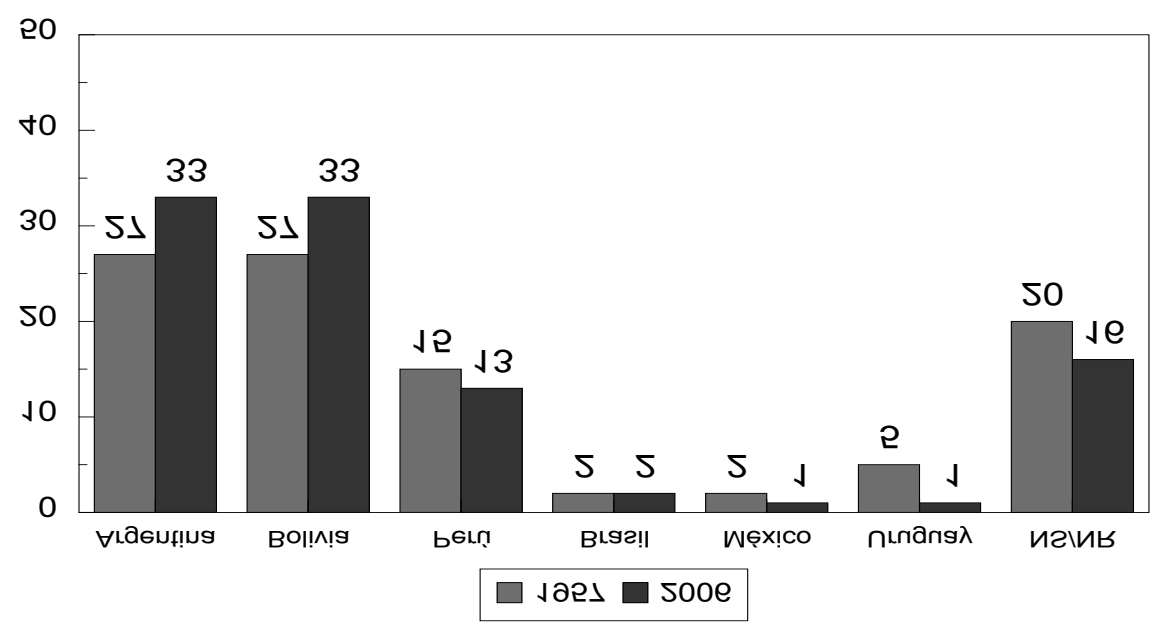

P. Entre los siguientes países de América Latina, ¿̇por cuál tiene Ud. más simpatía?

Fuente: 1957: Girard, Alain y Samuel, Raúl Situación y perspectiva de Chile en Septiembre de 1957. Una investigación de opinión pública en Santiago. Santiago, Instituto de Sociología, Universidad de Chile, 1958, pag. 53. 2006: BARÓMETRO CERC, Agosto del 2006.

porcentaje de opiniones positivas en el grupo de naciones que fue considerado en el estudio, que incluía al Brasil, Perú, Bolivia, Uruguay y México. En efecto, un $30 \%$ de los chilenos respondía que era el país hacia el cual tenía más simpatía $(30 \%)$, seguido a considerable distancia por México, que obtenía un $23 \%$ de menciones. Brasil recibía un porcentaje similar $(21 \%)$, mientras que los otros tres países, especialmente Perú, recibían escasas menciones (gráfico 1).

Sin embargo, Argentina también ocupaba el primer lugar como país que gozaba de menos simpatías (27\%), posición compartida con Bolivia, con el cual Chile tiene una historia conflictiva por la guerra del Pacífico, que implicó para el primero la pérdida de la provin- cia de Antofagasta y que recibía un similar porcentaje de menciones. Ambos eran seguidos a considerable distancia por Perú $(13 \%)$ mientras que los otros tres países tenían un número insignificante de menciones (gráfico 2).

Este perfil de opiniones es muy distinto del que se dio en la encuesta de 2006 cuando aplicamos las mismas preguntas. Argentina dejaba de estar en el primer lugar y se situaba en un tercer lugar, cayendo 21 puntos para recibir apenas un 9\% de menciones como el país hacia el cual los chilenos tenían más simpatía. El primer lugar era ocupado por Brasil, que aumentó 17 puntos, alcanzando al 38\%. México se mantuvo (24\%), Perú descendió al 1\% y Bolivia recibió un 3\% de menciones. 
GRÁfICO 2

PAÍses latinOAMERICANOS QUE GOZAN DE MENOS SIMPATÍAs, I957-2006

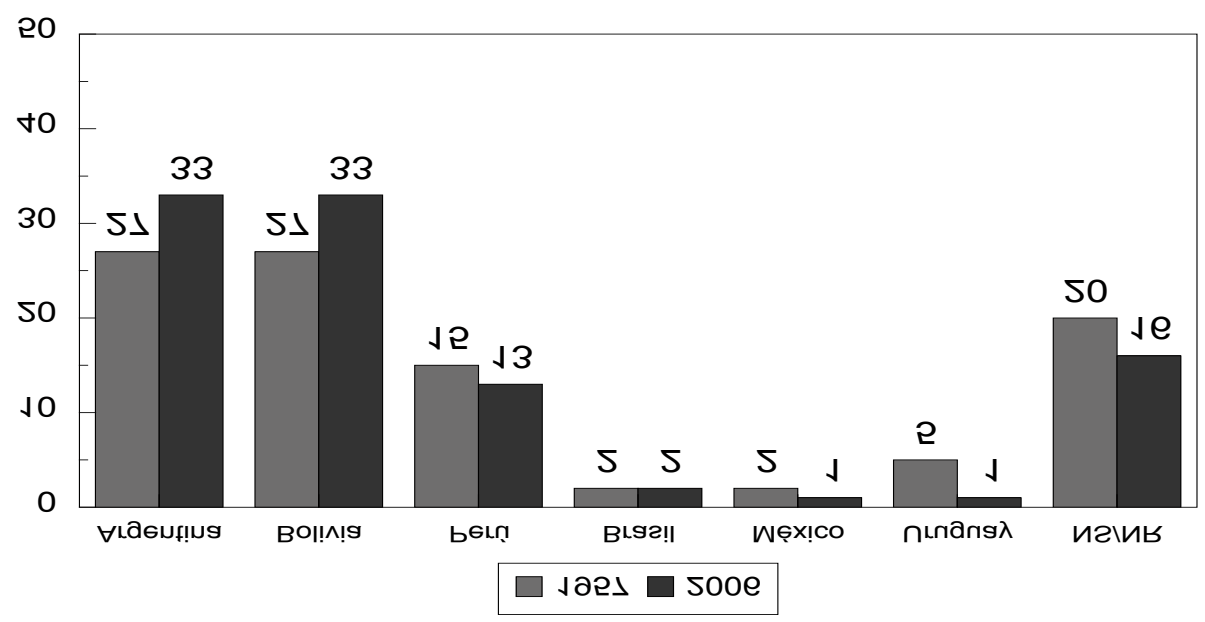

P. ¿Y por cuál tiene menos simpatía?

Fuente: 1957: La misma del gráfico 1. 2006: Barómetro CERC.

Un porcentaje mayor y significativo $(19 \%)$ no sabe o no responde.

La respuesta a la pregunta sobre cuál que goza de menos simpatías, no varió de manera importante entre las mediciones de 1957 y de 2006. Argentina continúa ubicándose en el primer lugar como el país que tiene menos simpatías, aunque esta vez lo comparte con Bolivia, que aumenta seis puntos, al 33\%, en comparación con la situación de hace medio siglo. Este cambio se puede explicar por las diferencias producidas durante la administración Lagos por la crisis política interna de Bolivia tras la caída del presidente Sánchez de Losada en 2004, pues su sucesor, el presidente Mesa, adoptó una abierta postura contra Chile por la demanda de salida al mar de su país, que se manifestó incluso en la Cumbre de las Américas de Monterrey, México, que fue respondida con energía por el presidente $\operatorname{Lagos}^{30}$. Le siguió Perú, a bastante distancia, con $13 \%$, y no hay menciones significativas de los otros tres países, Uruguay, México y Brasil. Un $16 \%$ no sabe o no responde.

Las opiniones críticas sobre Argentina son relativamente constantes a través de los grupos sociales y políticos, y su tono es relativamente más marcado entre los entrevistados de 26 a 40 años (37) y los votantes del PDC (38\%), que obtienen porcentajes superiores a la media. Bolivia, por su parte, tiene más

30 El discurso del presidente Mesa, así como la firme respuesta del primer mandatario chileno a la demanda de salida al mar de Bolivia, fueron difundidos por la televisión chilena y por diarios y radios, provocando enorme impacto en la opinión pública. 
Carlos Huneeus • Argentina y Chile: el conflicto del gas...

CuAdro 2

PAÍs LATINOAMERICANO POR EL QUE SIENTE MENOS SIMPATÍA (ARgENTINA Y BOLIVIA ÚNICAMENTE)*

\begin{tabular}{|c|c|c|}
\hline & Argentina & Bolivia \\
\hline \multicolumn{3}{|l|}{ Edad } \\
\hline $18-24$ & 36 & 28 \\
\hline $25-40$ & 31 & 32 \\
\hline $41-60$ & 37 & 34 \\
\hline 61 y más & 26 & 36 \\
\hline \multicolumn{3}{|l|}{ Género } \\
\hline Hombre & \multirow{2}{*}{$\begin{array}{l}34 \\
32\end{array}$} & \multirow{2}{*}{$\begin{array}{l}33 \\
33\end{array}$} \\
\hline Mujer & & \\
\hline \multicolumn{3}{|l|}{ Ingreso subjetivo } \\
\hline Alto & 36 & 30 \\
\hline Medio alto & 33 & 34 \\
\hline Medio bajo & 35 & 29 \\
\hline Bajo & 22 & 43 \\
\hline \multicolumn{3}{|l|}{ Intención de voto } \\
\hline UDI & \multirow[t]{5}{*}{28} & \multirow{5}{*}{$\begin{array}{l}43 \\
38 \\
26 \\
26 \\
35\end{array}$} \\
\hline $\mathrm{RN}$ & & \\
\hline PDC & & \\
\hline PPD & & \\
\hline PS & & \\
\hline Educación & & \multirow{4}{*}{$\begin{array}{l}35 \\
32 \\
29\end{array}$} \\
\hline Estudios primarios & 34 & \\
\hline Estudios Secundarios & 34 & \\
\hline Estudios Superiores & 32 & \\
\hline Total & 33 & 33 \\
\hline
\end{tabular}

rechazo entre los más pobres («tienen grandes dificultades» $(43 \%)$ y entre los votantes de la UDI $(43 \%)$.

En la encuesta de agosto del 2006 preguntamos sobre los presidentes a fin de conocer la opinión que tienen los chilenos del presidente Kichner. Este tiene una mala imagen entre los chilenos, la que se confirma con los resultados de las preguntas abiertas y cerradas que aplicamos. En la pregunta abierta ¿quién es el presidente más amigo de Chile?, Kirchner obtuvo el menor porcentaje de menciones $(4 \%)$, junto con el presidente de México, Vicente Fox, quien es poco conocido en Chile. El que recibió mayor porcentaje de respuestas fue el presidente 
del Brasil, Lula, con un $22 \%$, seguido a bastante distancia por el presidente Hugo Chávez de Venezuela, con un $8 \%$. Un 5\% de los encuestados mencionó al presidente Alan García, de Perú. Un alto porcentaje de encuestados ( $25 \%$ ) no mencionó a ningún presidente y $24 \%$ no respondió la pregunta.

Este resultado fue confirmado con la pregunta abierta sobre el presidente menos amigo de Chile, ya que el mayor porcentaje de menciones lo obtuvo el de Bolivia, Evo Morales, con un 34\%; seguido a solo cuatro puntos de distancia por su colega argentino, Nestor Kichner, con $30 \%$. En tercer lugar y a mucha distancia, se ubicaron el Jefe de Estado del Perú, Alan García, con 7\%, y Hugo Chavez de Venezuela, con $8 \%$.
Un 5\% no nombró a ninguno y un 16\% no respondió la pregunta.

Las preguntas abiertas tienen el inconveniente de que son respondidas por una parte de los entrevistados, que se caracterizan por ser más informados $y$, por ende, saben quienes son los presidentes de América Latina, cosa que no sucede con el resto de los entrevistados. De ahí la necesidad de utilizar preguntas cerradas, para permitir que un porcentaje más amplio de la población dé a conocer sus opiniones. Preguntamos la opinión sobre los presidentes Kirchner, Evo Morales de Bolivia, Lula de Brasil, Hugo Chávez de Venezuela y Alan García del Perú.

El presidente más amigo de Chile es el de Brasil con 55\% de menciones

\section{LOS PRESIDENTES LATINOAMERICANOS}

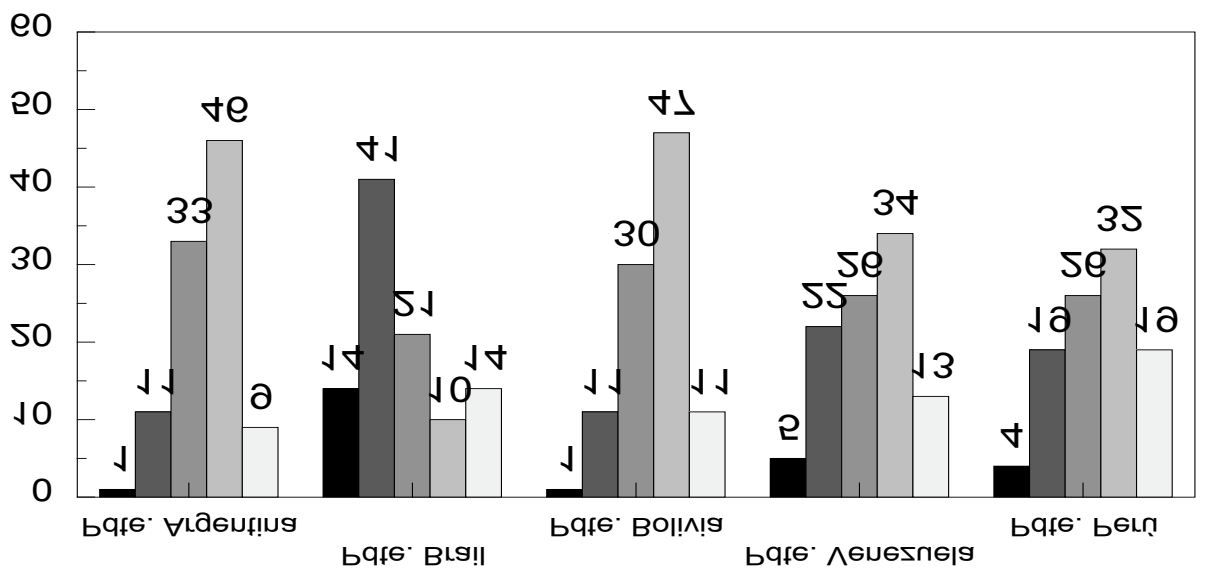

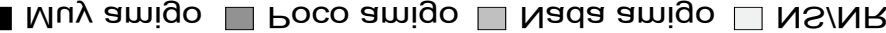 $\square$ घ|aेo swịa}

P. ¿Cuán amigo de Chile cree Ud. que es el presidente de Argentina, Nestor Krichner? ¿Diría Ud. que es... ¿Y el presidente Lula del Brasil? ¿Y el presidente Evo Morales de Bolivia? ¿Y el presidente Hugo Chávez de Venezuela? ¿Y el presidente Alan García del Perú?

Fuente: BARÓMETRO CERC, Agosto del 2006. 
Carlos Huneeus • Argentina y Chile: el conflicto del gas...

(suma de «muy amigo» y «algo amigo»), seguido del de Venezuela, con $27 \%$. Los presidentes de Argentina y de Bolivia reciben cada uno de ellos un $12 \%$ de menciones ( «muy amigo» por el contrario, reciben muy altas menciones negativas, $79 \%$ y $77 \%$, respectivamente, de respuestas "poco amigo» $\mathrm{y}$ «nada amigo».

Estos resultados confirman los cosy «algo amigo»). Kirchner y Morales, tos del conflicto del gas para Argentina

\section{CuAdro 3}

Grado de amistad hacia Chile de los presidentes de Argentina y Bolivia

\begin{tabular}{|c|c|c|c|c|c|c|c|c|}
\hline & \multicolumn{4}{|c|}{ Néstor Kirchner } & \multicolumn{4}{|c|}{ Evo Morales } \\
\hline & Muy & Algo & Poco & $\mathrm{Nada}$ & Muy & Algo & Poco & Nada \\
\hline Edad & & & & & & & & \\
\hline $18-24$ & 2 & 16 & 35 & 41 & 4 & 16 & 24 & 47 \\
\hline $25-40$ & 1 & 10 & 35 & 46 & 1 & 11 & 31 & 46 \\
\hline $41-60$ & 2 & 10 & 33 & 47 & 1 & 11 & 33 & 45 \\
\hline 61 y más & 1 & 8 & 28 & 52 & -- & 8 & 25 & 51 \\
\hline Género & & & & & & & & \\
\hline Hombre & 2 & 11 & 32 & 50 & 1 & 10 & 33 & 51 \\
\hline Mujer & 1 & 11 & 34 & 43 & 1 & 12 & 27 & 44 \\
\hline Ingreso Subjetivo & & & & & & & & \\
\hline Alto & 1 & 11 & 32 & 51 & 3 & 11 & 29 & 52 \\
\hline Medio alto & 1 & 11 & 34 & 50 & 1 & 11 & 31 & 50 \\
\hline Medio bajo & 2 & 11 & 33 & 46 & 2 & 9 & 31 & 46 \\
\hline Bajo & 1 & 11 & 22 & 44 & 1 & 11 & 24 & 43 \\
\hline Intención de voto & & & & & & & & \\
\hline UDI & -- & 7 & 23 & 64 & 1 & 5 & 23 & 62 \\
\hline $\mathrm{RN}$ & 2 & 6 & 31 & 56 & 3 & 6 & 30 & 57 \\
\hline PDC & -- & 12 & 37 & 46 & 2 & 17 & 33 & 40 \\
\hline PPD & -- & 14 & 32 & 48 & 1 & 8 & 36 & 47 \\
\hline PS & 4 & 13 & 35 & 45 & 1 & 14 & 31 & 46 \\
\hline Educación & & & & & & & & \\
\hline Estudios primarios & 1 & 9 & 32 & 45 & 0 & 8 & 26 & 48 \\
\hline Estudios Secundarios & 1 & 13 & 32 & 48 & 2 & 13 & 31 & 46 \\
\hline Estudios Superiores & 1 & 12 & 35 & 48 & 3 & 13 & 33 & 47 \\
\hline Total & 1 & 11 & 33 & 46 & 1 & 11 & 30 & 47 \\
\hline
\end{tabular}

P. ¿Cuán amigo de Chile cree Ud. que es el presidente de Argentina, Nestor Kirchner? ¿Diría Ud. que es... ¿Y el presidente Evo Morales de Bolivia?

y el presidente Kirchner en la opinión pública de Chile, que se ubican en una situación similar a la de Bolivia, país con el cual Chile en el siglo XIX tuvo un

conflicto bélico que mantiene su presencia latente en la sociedad chilena. 
CONSECUENCIAS ECONÓMICAS PARA CHILE DE LA CRISIS DEL GAS

Las restricciones e interrupciones en el envío de gas natural desde Argentina ha impactado la economía nacional, principalmente a través del aumento del costo de la energía. Sin embargo, cabe señalar que mucho más costoso ha resultado para la economía chilena el aumento de los precios internacionales del petróleo y del carbón, que supera con mucho las consecuencias económicas de la falta de gas argentino. Si bien los cortes comenzaron en 2004, fue durante 2006 cuando se registraron los niveles más altos, superando el $50 \%$ de los requerimientos normales. En el gráfico 3, se observa el porcentaje que alcanzaron las restricciones de gas respecto de los niveles requeridos y se aprecia que hacia fines de 2006 hubo recortes superiores al $80 \%$ de las necesidades nacionales. El impacto en la economía nacional a causa de estas restricciones ha mermado el potencial de crecimiento del país, reduciendo las tasas de crecimientos de la industria y el PIB.

Las restricciones al envío de gas natu-

\section{GRÁFICO 3}

Restricciones de los envíos de gas Desde Argentina, 2004 - 2007

(EN PORCENTAJES RESPECTO DE REQUERIMIENTOS NORMALES)

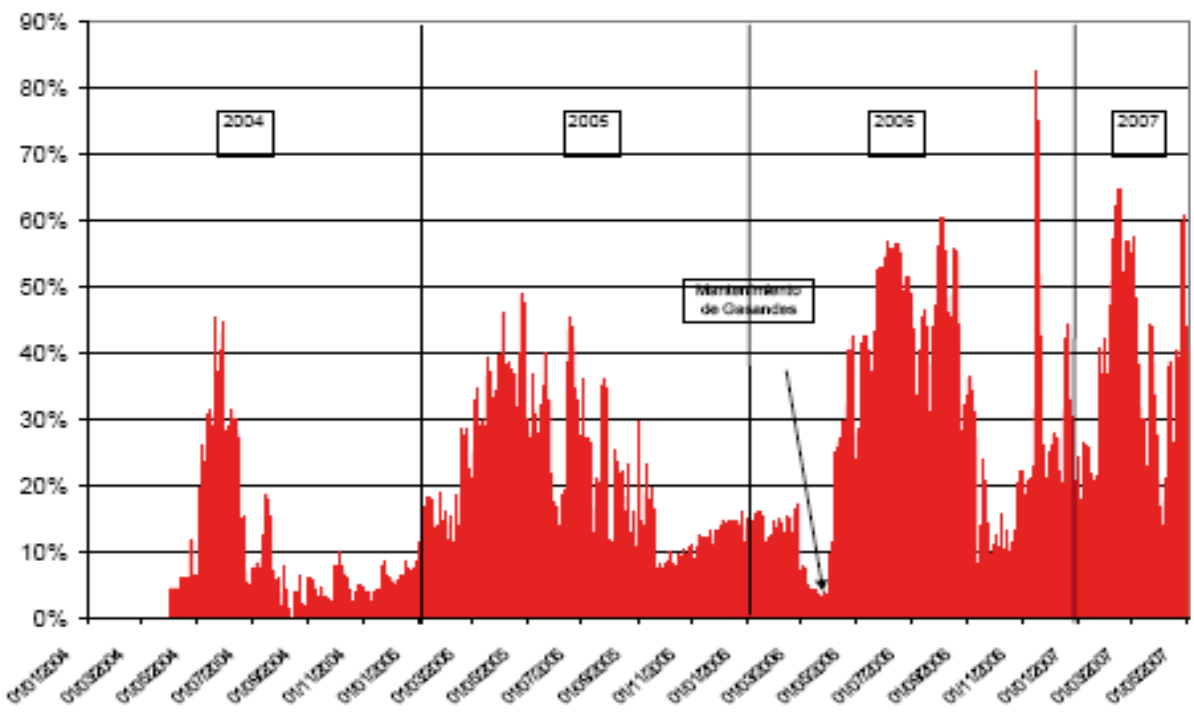

Fuente: Comisión Nacional de Energía

ral a Chile han tenido como consecuencia un aumento en el costo de la energía, en particular de la energía eléctrica. Sin em- bargo, la prinmcipal fuente de mayores costos energéticos ha sido el aumento de los costos del petróleo y del carbón a nivel 
internacional. Estas alzas se vinculan con otros aumentos de precios beneficiosas para Chile, como es el caso de los precios del cobre y de la celulosa. aumento de su valor se traduce en una disminución del ingreso disponible ${ }^{31}$. A nivel agregado, esta disminución del ingreso disponible implica una disminución en el consumo de bienes producidos interna y externamente. En el caso del primero acarrea una caída en el PIB.

Una de las principales interrogantes planteadas por la crisis del gas ha sido su impacto en la economía chilena. En su informe de Política Monetaria de septiembre de 2006, el Banco Central recogía los efectos que estaban teniendo las restricciones argentinas en la industria manufacturera, particularmente en los márgenes de explotación ${ }^{32}$.

El Informe de Política Monetaria de enero de 2007 del Banco Central de Chile incluyó un estudio sobre los efectos que ha tenido el mayor costo de la energía en la producción industrial y el producto interno ${ }^{33}$. Para ello, se analizó el crecimiento de la producción industrial y la economía el año

31 La reducción del ingreso disponible puede compensarse con créditos externos.

32 Ingresos de explotación menos costos de explotación.

33 El costo de la energía es dado por el costo del petróleo y el gas natural. Este informe presenta los resultados correspondientes a los efectos que han tenido las restricciones en el suministro de gas natural en la economía. Para ver los efectos que representó el mayor valor del petróleo, ver Banco Central de Chile, Informe de Política Monetaria, Enero 2007, pp. 39-40.
2006, y se comparó con el potencial de crecimiento que hubiese tenido en condiciones «normales» ${ }^{34}$.

En 2006, la economía chilena enfrentó un escenario marcado por los mayores costos de la energía por la escalada internacional del precio del petróleo $^{35}$ y por las restricciones en la entrega de gas natural proveniente de Argentina. Sus efectos se tradujeron en variaciones anuales promedio de $11.2 \%$ y $7.1 \%$ en los precios internos de los combustibles derivados del petróleo y la electricidad, respectivamente. Al respecto, no hay que equivocarse respecto del origen de las alzas de precios de los combustibles: desde comienzos de 2004 a la fecha, los precios del petróleo y del carbón han aumentado más de $100 \%$ a nivel mundial (el mismo período del desabastecimiento argentino).

El principal sector perjudicado por esta situación ha sido la industria manufacturera, que ha experimentado un aumento de sus costos por concepto de energía, proveniente tanto de las restricciones del suministro de gas argentino como del aumento internacional del precio del petróleo.

34 El cálculo que realizó el Banco Central utilizó una estimación del crecimiento que hubiese registrado cada rama industrial si en 2006 el precio de la energía hubiese sido el valor de referencia de 2005. La diferencia entre el valor estimado y el real correspondería a una estimación del efecto que tuvieron en el crecimiento industrial las restricciones del gas argentino.

35 El petróleo promedió un máximo nominal de 74.3 dólares por barril WTI en julio. 
$\mathrm{Al}$ analizar los márgenes de explotación de la industria se observa que en los últimos años estos han tenido una caída importante, la que se vincularía al mayor costo de la energía. En el gráfico 2 podemos apreciar la evolución de dichos márgenes para la industria nacional en el período 1995-2005. De acuerdo con esta información, las empresas han estado absorbiendo una parte de los mayores costos de producción sin traspasarlos a sus clientes.

Por otra parte, la menor disponibilidad de energéticos y su mayor valor disminuyen la capacidad productiva de la industria. De acuerdo con las estimaciones del Banco Central, la de esta rama creció de un $1.27 \%$ a $2.56 \%$ menos a causa de las restricciones del suministro de gas argentino. Esto quiere decir que en Chile la actividad industrial debió haber crecido entre un 3.8\% y un $5 \%$ en 2006 , en vez del $2.53 \%$ que se registró en la realidad.

Cuando se analizan los efectos de la crisis del gas en la economía chilena a nivel agregado se aprecia que los que esta generó en la industria no son los únicos. "Aunque resulta difícil precisar su efecto sobre el agregado de la economía, se presume que es mayor del que puede derivarse directamente de la producción industrial y que implica alrededor de 0.2 punto porcentual de menor crecimiento del PIB en el 2006 ${ }^{36}$.

Las estimaciones sobre el impacto de la crisis basadas en los efectos que

36 Banco Central de Chile, Informe de Política Monetaria, enero de 2007. tuvo la industria nos muestran que en 2006 el PIB chileno debió crecer entre un $4.35 \%$ y un $4.51 \%$, en vez del $4.2 \%$ real. Si bien esta diferencia puede considerarse pequeña, es significativa pues representa entre un $4 \%$ y un $7 \%$ del crecimiento anual del país.

Es importante tener presente que la crisis del gas se da en un contexto adverso de la economía nacional por las alzas de precio del petróleo, que agravan el impacto de la crisis del gas. Sin embargo, el precio del cobre aumentó mucho ás que el del petróleo. Además, no hemos perdido competitividad internacional, puesto que todo el mundo se ha visto afectado por las alzas de precio del petróleo, del GNL y del carbón.

\section{Conclusiones}

Las restricciones a los envíos de gas natural argentino a Chile producidos desde el 2004 se explican por factores políticos internos de Argentina, que tuvieron que ver con las decisiones adoptadas por el gobierno para enfrentar la grave crisis económica del 2001 y el difícil escenario posterior para conseguir la consolidación del orden político y superar las graves dificultades económicas. La prioridad del gobierno trasandino del presidente Kirchner fue resolver los problemas económicos internos sin atender mayormente a las repercusiones internacionales de sus decisiones. No se trató de una política contra Chile, sino de que optó por satisfacer las necesidades de la demanda interna, en la cual la demanda 
residencial, especialmente de Buenos Aires, era muy importante. Es probable que ante una disyuntiva similar-respetar un acuerdo internacional- provocando el desabastecimiento de una mayoría de la población, en Chile cualquier gobierno habría optado por los intereses internos, aunque seguramente lo habría hecho de manera más transparente y sin los costos adicionales de representaron los impuestos aplicados a las empresas. La política trasandina dañó la imagen del país y del presidente Kirchner en la opinión pública chilena, que se ha mostrado crítica de los políticos y de la realidad argentina.

En un sistema político con insuficiente grado de institucionalización, la alta centralización decisoria del presidente argentino le permite adoptar estas decisiones, que tienen elevados costos para los países asociados. El gobierno del presidente Lagos adoptó una política de prudencia para obtener seguridades de que se mantendrían los compromisos entre los dos países y las empresas privadas y adoptó medidas de largo plazo para lograr la independencia del gas trasandino a través del gas natural licuado.
Durante los siete años en que se exportó el gas natural en los volúmenes acordados, la economía chilena se vio beneficiada porque se produjo una caída de los precios de la energía, lo que demuestra que independiente del conflicto producido, la iniciativa fue exitosa.

El conflicto tuvo importantes consecuencias para Chile respecto del futuro de su matriz energética para disminuir la dependencia del gas argentino, pues junto con los proyectos hidroeléctrico se inició un importante proyecto para usar gas natural licuado, se puso mayor énfasis que antes en el papel del carbón, se adoptaron medidas para promover diversas fuentes de energía, que se han traducido en numerosas inversiones por nuevos actores y hasta se ha planteado la necesidad de estudiar el uso de la energía nuclear como alternativa de largo plazo. El conflicto del gas terminará fortaleciendo la base energética del país, aunque a un costo que pudo haber sido menor si hubiera habido mayor previsión de parte de las autoridades de gobierno y del sector privado involucrados en este negocio.

CuAdro 4

Gas natural exportado desde Argentina a través de Sistema de TRANSPORTE, 2004-2006 (MILES DE M³ DE $9300 \mathrm{KCAL}$ )

\begin{tabular}{|l|c|c|c|c|c|c|c|}
\hline & & Gas Andes & Norandino & EGS & Methanex YPF & \multirow{2}{*}{$\begin{array}{c}\text { Total } \\
\text { Chile }\end{array}$} & $\begin{array}{c}\text { Gxportado por } \\
\text { Argentina }\end{array}$ \\
\hline Mes & Año & TGN & TGN & TGS & TGS & & 346352 \\
\hline Enero & 2004 & 234396 & 68693 & 0 & 0 & 303089 & 327227 \\
\hline Febrero & 2004 & 227002 & 62535 & 0 & 0 & 289537 & 387757 \\
\hline Marzo & 2004 & 266770 & 78497 & 0 & 0 & 345267 & \multicolumn{2}{c|}{ Exportaciones } \\
\hline
\end{tabular}


Estudios Internacionales 158 (2007) • Universidad de Chile

\begin{tabular}{|c|c|c|c|c|c|c|c|}
\hline & & Gas Andes & Norandino & EGS & Methanex YPF & Total & Total Exportado \\
\hline Mes & Año & TGN & TGN & TGS & TGS & Chile & por Argentina \\
\hline Abril & 2004 & 228531 & 71316 & 0 & 0 & 299847 & 340954 \\
\hline Mayo & 2004 & 213186 & 61887 & 0 & 0 & 275073 & 298231 \\
\hline Junio & 2004 & 226631 & 62205 & 0 & 0 & 288836 & 313469 \\
\hline Julio & 2004 & 264159 & 64424 & 0 & 0 & 328583 & 340776 \\
\hline Agosto & 2004 & 275568 & 52648 & 0 & 0 & 328216 & 339457 \\
\hline Septiembre & 2004 & 232650 & 74322 & 0 & 0 & 306972 & 374334 \\
\hline Octubre & 2004 & 216887 & 72618 & 0 & 0 & 289505 & 374075 \\
\hline Noviembre & 2004 & 233893 & 61133 & 0 & 0 & 295026 & 383806 \\
\hline Diciembre & 2004 & 240470 & 75702 & 0 & 0 & 316172 & 407306 \\
\hline Enero & 2005 & 220104 & 80358 & 0 & 0 & 300462 & 384495 \\
\hline Febrero & 2005 & 193012 & 69681 & 0 & 0 & 262693 & 306690 \\
\hline Marzo & 2005 & 164835 & 77182 & 0 & 0 & 242017 & 259619 \\
\hline Abril & 2005 & 116205 & 73753 & 0 & 0 & 189958 & 215079 \\
\hline Mayo & 2005 & 164111 & 75976 & 16152 & 0 & 256239 & 260585 \\
\hline Junio & 2005 & 172840 & 74493 & 24315 & 0 & 271648 & 278619 \\
\hline Julio & 2005 & 147334 & 61823 & 27151 & 0 & 236308 & 244042 \\
\hline Agosto & 2005 & 159520 & 60730 & 22771 & 0 & 243021 & 252167 \\
\hline Septiembre & 2005 & 144966 & 76840 & 29053 & 0 & 250859 & 265038 \\
\hline Octubre & 2005 & 161463 & 82680 & 31081 & 0 & 275224 & 357392 \\
\hline Noviembre & 2005 & 154710 & 70109 & 30070 & 0 & 254889 & 320743 \\
\hline Diciembre & 2005 & 174490 & 72912 & 29333 & 0 & 276735 & 359705 \\
\hline Enero & 2006 & 197343 & 30976 & 30976 & 0 & 298153 & 378729 \\
\hline Febrero & 2006 & 193638 & 26777 & 26777 & 0 & 279314 & 341572 \\
\hline Marzo & 2006 & 212018 & 21193 & 21193 & 0 & 302548 & 382774 \\
\hline Abril & 2006 & 180451 & 27010 & 27010 & 0 & 253033 & 284695 \\
\hline Mayo & 2006 & 126542 & 31107 & 31107 & 0 & 210352 & 222263 \\
\hline Junio & 2006 & 108988 & 29813 & 29813 & 0 & 175308 & 192970 \\
\hline Julio & 2006 & 150950 & 15919 & 15919 & 47062 & 261797 & 278578 \\
\hline Agosto & 2006 & 112683 & 29128 & 29128 & 55514 & 232648 & 244738 \\
\hline Septiembre & 2006 & 135660 & 15908 & 15908 & 53752 & 248552 & 296684 \\
\hline Octubre & 2006 & 137223 & 17960 & 17960 & 61215 & 275706 & 350648 \\
\hline Noviembre & 2006 & 123254 & 11061 & 11061 & 48997 & 231208 & 305618 \\
\hline Diciembre & 2006 & 167766 & 12400 & 12400 & 59281 & 287864 & 362983 \\
\hline \multicolumn{2}{|l|}{ Total 2004} & 2860143 & 805980 & 0 & 0 & 3666123 & 4233744 \\
\hline \multicolumn{2}{|l|}{ Total 2005} & 1973590 & 876537 & 209926 & 0 & 3060053 & 3504174 \\
\hline \multicolumn{2}{|l|}{ Total 2006} & 1846516 & 614893 & 269252 & 325821 & 3056482 & 3642253 \\
\hline
\end{tabular}

\section{BibLIOGRAFÍA}

Cheibub, José Antonio (2007). Presidentialism, Parliamemtarism, and Democracy. (Cambridge: Cambridge University Press).

Curia, Walter (2006). El último peronista.
La cara oculta de Kirchner. Buenos Aires; Editorial Sudamericana.

Ferreira Rubio, Delia y Matteo Goretti (1996). "Cuando el presidente gobierna solo. Menem y los decretos de necesidad y urgencia hasta la Reforma Constitucional (Julio 1989-Agosto 1994)», Desarrollo 
Económico, vol. 36, 141, abril-junio, pp. 443-474.

Figueroa, Eugenio y Birgitta Smith (2002). Natural Gas Across the Andes. A case Study of an International Business Venture. Edmonton, University of Alberta.

Gadana, Nicolás (2000). «Determinantes de la inversión en el sector petróleo y gas en la Argentina", en: Herman, Daniel y Bernardo Kosacoff (eds.), La Argentina de los noventa. Buenos Aires: Eudeba/ CEPAL, tomo II.

Galetovic, Alexander, Juan Ricardo Hinostroza y Cristián Marcelo Muñoz (2004). «Gas y electricidad, ¿qué hacer ahora?»,en Estudios Públicos, primavera.

Gamboa, Ricardo y Carlos Huneeus. (2007). «La interconexión gasífera Chile-Argentina: sus objetivos y actores", Estudios Internacionales, $\mathrm{N}^{\circ} 157$, Año XL.

Huneeus, Carlos. (2000). «Los cambios institucionales al sistema económico durante la transición a la democracia en Chile: Del neoliberalismo a la economía social de mercado», Revista de Ciencia Política, vol. XX, 2.

_ presidencialismo en Chile?», Persona y Sociedad, vol. XIX, N 2, agosto.

_, (2004) y Fabiola Berríos. «El Congreso Nacional en un régimen presidencial. El caso de Chile», en Revista de Derecho Público, 66.

__ El caso de Chile». (2005). Revista SAAP. Publicación de Ciencia Política de la Sociedad Argentina de Análisis Político, Vol. 2, No 2, Buenos Aires, septiembre.

Huneeus, Carlos, Fabiola Berríos y Rodrigo Cordero (2006). "Legislatures in presidential systems: The Latin American experience», Journal of Legislative Studies, vol. 12, 3-4, septiembre-diciembre.

Huntington, Samuel P. (1968). Political Order in Changing Society, New Haven, Yale University Press.

Kloten, Norbert (1991), Die Transformation von Wirtschaftsordnungen, Tübingen: J.C. Mohr (Paul Siebeck).
Lamounier, Bolivar (2003), «Brazil: An Assessment of the Cardozo Administration", en: Domínguez, Jorge I. y Michael Shifter (eds.) Constructing Democratic Governance in Latin America. Baltimore: The Johns Hopkins University Press.

Llanos, Mariana (2001), «Understanding Presidential Power in Argentina: a Study of the Policy of Privatization in the 1990s", Journal of Latin American Studies vol. 33:1, febrero.

Llanos, Mariana y Ana Margheritis (1999), «Liderazgo Presidencial y dinámica institucional durante el primer período presidencial de Menem. El caso de las Privatizaciones», en Política y Gobierno, Vol. 6, № 2.

Lowi, Theodore (1985), The Personal Presidency, Ithaca, Cornell University Press.

Mainwaring, Scott y Matthew Soberg, en Shugart (eds.) (1997), Presidentialism and Democracy in Latin America, Cambridge: Cambridge University Press.

Mustapic, Ana María (2000), «Oficialistas y diputados: las relaciones ejecutivo-legislativo en la Argentina", Desarrollo Económico, vol. 39, $\mathrm{N}^{\circ} 156$, enero-marzo.

—, (2005). «Inestabilidad sin colapso. La renuncia de los presidentes: Argentina en el año 2001», Desarrollo Económico vol. $45, \mathrm{~N}^{\circ} 178$, julio-septiembre.

Nacrur Gazali, Miguel Angel (2001), «El Banco Central de Chile», en: Navarro Beltrán, Enrique (ed.), 20 años de la Constitución chilena 1981-2001, Santiago: Universidad Finis Terrea-LexisNexis Chile.

Negretto, Gabriel L. (2001). «Negociando los poderes del presidente: reforma y cambio constitucional en la Argentina", Desarrollo Económico, vol. 41, N 163 , octubre-diciembre.

—, (2002). «¿Gobierna solo el Presidente? Poderes de decreto y diseño institucional en Brasil y Argentina", Desarrollo Económico, vol. 42, $\mathrm{N}^{\circ} 167$, octubre-diciembre.

Neustadt, Richard E. (1990). Presidencial Power and the Modern Presidents. The Politics of Leadership from Roosevelt to Reagan. Nueva York, The Free Press (1a edición de 1960). 
Novaro, Marcos (comp.) (2002). El derrumbe político en el ocaso de la convertibilidad. Buenos Aires; Grupo Editorial Norma.

Pfeffer Urquiaga, Emilio (2005). Reformas constitucionales 2005, Santiago: Editorial Jurídica de Chile.

Quiroga, Hugo (2006), La Argentina en emergencia permanente, Buenos Aires: Edhasa.

Rodríguez Elizondo, José (2006), Las crisis vecinales del gobierno de Lagos, Santiago: Random House Mondadori.
Serrafero, Mario D. (2005), Exceptocracia. ¿Confín de la democracia? Intervención federal, estado de sitio y decretos de necesidad y urgencia. Buenos Aires: Lumiere. Shugart, Matthew Soberg y John M., Carey. (1992), Presidents and Assemblies. Constitutional Design and Electoral Dynamics, Cambridge: Cambridge University Press. Waisman, Carlos H. (2003), «El default argentino: sus causas institucionales", Política y Gobierno, vol. X, N 1 , I semestre. 